\title{
O Referencial Teórico na Construção dos Questionários Contextuais do Saeb 2001
}

\author{
CRESO FRANCO \\ Professor do Departamento de Educação da PUC-Rio \\ (creso@edu.puc-rio.br) \\ CRISTIANO FERNANDES \\ Professor do Departamento de Engenharia Elétrica da PUC-Rio \\ (cris@ele.puc-rio.br) \\ JOSÉ FRANCISCO SOARES
}

Professor do Departamento de Estatística e do Programa de Pós-Graduação da UFMG

(jfsoares@icex.ufmg.br)

KAIZÔ BELTRÃO

Professor da Escola Nacional de Ciências Estatísticas

(kaizo@ibge.gov.br)

MARIA EUGÊNIA BARBOSA

Professora da Universidade da Beira Interior (Portugal)

(meferrao@noe.ubi.pt)

MARIA TEREZA GONZAGA ALVES

Doutoranda do Programa de Pós-Graduação em Educação da UFMG

(mtga@est.ufmg.br)

\begin{abstract}
Resumo
Descreve-se o referencial teórico que baseou a definição dos questionários contextuais do Saeb 2001. Explicita-se a literatura considerada particularmente relevante, especificam-se os construtos privilegiados e mapeia-se o modo pelo qual os construtos privilegiados se relacionam com os itens dos questionários. Justifica-se a relevância da existência de referencial teórico tanto sob o ponto de vista da qualidade das medidas do Saeb 2001 quanto das possibilidades que se abrem para o contínuo aprimoramento dos questionários contextuais.
\end{abstract}

Palavras-chave: avaliação da educação, questionários, política educacional. 


\section{Resúmen}

El artículo describe el referencial teórico en que se basó la definición de los cuestionarios del Saeb 2001. Se relaciona la literatura que se consideró particularmente de relieve, se especifican los constructos privilegiados y se mapea el modo como los constructos privilegiados están relacionados con los puntos de los cuestionarios. Se justifica la importancia de la existencia del referencial teórico, tanto bajo el punto de vista de la calidad de las medidas del Saeb 2001, como por las posibilidades que se abren para el contínuo perfeccionamiento de los cuestionarios contextuales.

Palabras-clave: evaluación de la educación, cuestionarios, política educativa.

\section{Abstract}

This paper describes the theoretical framework for the design of the Saeb 2001 contextual questionnaires. The relevant literature is discussed and the constructs to be measured are listed. The link between constructs and items is shown. It is emphasized that a theoretical framework was fruitful in terms of both the quality of the measures in Saeb 2001 and the continuous process of enhancing Saeb instruments.

Key words: assessment, questionnaires, educational policy. 


\section{INTRODUÇÃO}

O presente artigo baseia-se em trabalho desenvolvido pelos autores, por encomenda do Inep/MEC, que demandava a construção de um quadro de referência conceitual para os questionários contextuais do Saeb, para permitir não apenas o aprimoramento dos referidos questionários que viriam a ser utilizados no Saeb 2001 mas também a consolidação de base para o posterior processo de contínuo aprimoramento dos questionários em novas realizações do Saeb. A iniciativa de publicação deste trabalho, em periódico acadêmico da área de educação, justifica-se tanto pela renovação do interesse da comunidade de pesquisa em educação por surveys educacionais (Esposito, Davis, Nunes 2000, Barbosa, Fernandes 2001) quanto pelo crescimento da reflexão sobre o papel dos questionários na pesquisa educacional (Brandão, 2000).

O Saeb tem como principal objetivo avaliar a educação brasileira, a fim de contribuir para a melhoria de sua qualidade e para a universalização do acesso à escola, oferecendo subsídios concretos para a formulação, reformulação e o monitoramento das políticas públicas voltadas para a educação básica. Além desse objetivo, o Saeb procura também:

“- oferecer dados e indicadores que possibilitem maior compreensão dos fatores que influenciam o desempenho dos alunos, nas diversas séries e disciplinas;

- proporcionar aos agentes educacionais e à sociedade uma visão clara e concreta dos resultados dos processos de ensino e aprendizagem e das condições em que são desenvolvidos;

- desenvolver competência técnica e científica na área de avaliação educacional, incentivando o intercâmbio entre instituições de ensino e pesquisa e administrações educacionais; $e$

- consolidar uma cultura de avaliação nas redes e instituições de ensino." (Inep, 2001)

Os mencionados objetivos envolvem uma complexa cadeia de ações, que incluem a implementação de procedimentos voltados para:

i. o acompanhamento do que os estudantes brasileiros estão aprendendo;

ii. o acompanhamento de como os resultados educacionais distribuem-se em função da origem social dos alunos;

iii. o acompanhamento de como evoluem as condições de qualidade da escolarização; 
iv. o acompanhamento de como as condições de qualidade da escolarização se distribuem em função da origem social dos alunos;

v. a investigação de que fatores escolares promovem eficácia e equidade na educação brasileira.

A implementação desses cinco aspectos envolve a obtenção de medidas cognitivas, que captem o que os alunos aprendem, e de medidas contextuais, que captem a origem social dos alunos e as condições em que eles estudam. As primeiras - medidas cognitivas - envolvem os testes do Saeb; as últimas - medidas contextuais - envolvem os questionários que o Saeb aplica a alunos, professores, diretores e escolas. Este documento envolve primordialmente a definição e explicitação de um quadro de referência para os questionários contextuais do Saeb. O propósito da definição de quadro de referência conceitual para os instrumentos contextuais do Saeb é a definição, explicitação e justificação dos construtos que se pretende captar pela aplicação dos instrumentos contextuais. A publicação do quadro de referência não tem a intenção de consolidar e fechar os instrumentos contextuais do Saeb. Ao contrário, objetiva não só fornecer base para a continuidade do debate sobre a pertinência do próprio quadro de referência aqui delineado, mas também estimular avaliações acerca de até que ponto os questionários do Saeb 2001 explicitam adequadamente os construtos privilegiados no quadro de referência. Por este meio, espera-se viabilizar um processo de contínuo aprimoramento dos questionários contextuais.

Na seqüência, apresenta-se a metodologia de trabalho que levou tanto à definição do quadro de referência quanto dos questionários contextuais. Prossegue-se com a discussão da literatura relevante. Concluise com a explicitação dos construtos priorizados e com recomendações que poderão vir a ser contempladas em futuras atualizações desse trabalho. No anexo encontra-se o mapeamento dos construtos com os itens dos questionários.

\section{METODOLOGIA}

Em estudos de avaliação da educação, os questionários contextuais desempenham o papel de oferecer fatores explicativos para a modelagem da proficiência dos alunos, medida pelos instrumentos cognitivos. Alguns autores têm enfatizado a relevância de um papel complementar para os questionários contextuais: a produção de indicadores de qualidade das 
condições de escolarização e a modelagem de como esses indicadores se distribuem entre alunos de origem sociodemográfica distinta (Raudenbush, Randall, Cheong 1998) . Ambos os propósitos envolvem a priorização de construtos que caracterizem adequadamente o perfil sociodemográfico dos alunos, bem como suas condições de estudo. Em primeira instância, isto envolve a identificação de fatores que captem o que importa para a aprendizagem do aluno. Em seguida, envolve a construção de questionários que operacionalizem esses fatores.

A definição dos construtos a serem priorizados deve se beneficiar de teorias e de resultados de pesquisas educacionais. Resultados de outras pesquisas que focalizam o efeito escola são bastante importantes e, por isso, incluímos em nossa revisão estudos que produziram sínteses acerca dos fatores associados ao desempenho escolar e à escola eficaz. Este tipo de investigação teve grande impulso na literatura internacional a partir dos anos 80, sobretudo nos Estados Unidos e Inglaterra. Alguns autores alertam para os problemas advindos da derivação de contribuições para políticas educacionais de países - em especial do terceiro mundo - com base em resultados de pesquisas realizadas em outros países. Esse tipo de observação é pertinente e é precisamente para evitar o risco a ele associado que nos preocupamos em incluir no questionário brasileiro - visando a posterior testagem empírica - construtos relacionados com achados de outros contextos. Além disso, incluímos em nossa revisão de literatura artigos que relatam pesquisas brasileiras. Quanto a essas, nosso esforço começou com a inclusão de artigos que reportam análises com base em dados do Saeb ou do Saresp. Certamente a existência de avaliações em larga escala como o Saeb constituem uma oportunidade para a criação de uma referência empírica importante para a reflexão nacional sobre o assunto. Na conclusão desse trabalho, apresentamos uma síntese dos artigos revistos e cotejamos as conclusões com achados da pesquisa nacional qualitativa. Esta opção pareceu-nos relevante tanto por causa da ainda pequena tradição brasileira com estudos quantitativos quanto pelos benefícios associados ao adensamento das relações entre pesquisas conduzidas com base em metodologias distintas. As pesquisas qualitativas priorizadas em nossa revisão são aquelas que reportam resultados passíveis de serem incorporados em questionários de pesquisas de levantamento.

A construção dos instrumentos levou em consideração que poucas modificações na estrutura do processo de coleta de dados poderiam ser implementadas já no Saeb 2001. Por isso, trabalhou-se com a noção de que dados seriam coletados por meio dos questionário do aluno, do professor, da turma, do diretor e da escola. No futuro, será importante poder 
incorporar dados dos registros escolares e de curtos questionários para pais ou responsáveis. Modificações de menor monta serão incorporadas ao processo de coleta de dados, para garantir menor percentual de dados faltantes no questionário do professor e maior número de professores respondentes em cada escola.

É importante ressaltar que o quadro de referência conceitual e os questionários contextuais do Saeb 2001 não foram produzidos de modo seqüencial. Ainda que tivéssemos começado pela revisão de literatura, desde muito cedo passamos a considerar outros questionários de pesquisas de levantamento e a delinear as versões iniciais do questionário para o Saeb 2001. Ao final de maio de 2001 uma versão preliminar foi submetida à discussão com a equipe do Inep/MEC e com consultores. Posteriormente, avaliou-se o funcionamento dos itens que já tinham sido utilizados em outros exercícios de avaliação do Saeb e submeteram-se os questionários a pré-testagem, que teve por objetivo verificar os procedimentos de aplicação, a avaliação empírica do funcionamento dos itens em relação a dados faltantes e à conferência da viabilidade de construção de escalas à luz dos padrões de resposta obtidos. Em julho de 2001, consolidou-se a versão definitiva dos questionários contextuais do Saeb 2001.

\section{CARACTERÍSTICAS ESCOLARES E DESEMPENHO ESCOLAR}

Abordamos a literatura relevante com base em seis trabalhos de revisão de literatura. Quatro deles são revisões produzidas nos EUA (Lee, Bryk, Smith 1993; Mayer, Mullen, Moore, 2000), no Canadá (Willms, 1992) e na Inglaterra (Sammons, Hillman, Mortimore, 1995) enquanto duas das revisões foram produzidas por autores brasileiros (Mello, 1994; MEC, 1998). Incluímos também uma síntese da ainda pequena literatura que aborda o tema do efeito escola com base em dados das pesquisas contemporâneas de avaliação da educação. Em seguida, buscamos sintetizar os diversos trabalhos aqui revistos, com o propósito de apontar os construtos a serem priorizados pelos questionários do Saeb 2001. Neste contexto, procuramos cotejar os achados da mencionada literatura com aqueles reportados pela literatura educacional qualitativa contemporânea.

A revisão que segue é centrada nas características escolares e sua relação com resultados escolares dos alunos. Esta revisão inclui, ainda, o tema da relação de escolas com famílias mas não inclui o tema da relação de diferenças de origem socioeconômica e resultados escolares. Isso não significa que esse aspecto tenha sido negligenciado. Ao contrário, desde há muito tem sido enfatizado que aspectos socioeconômicos e demográficos 
têm grande influência nos resultados educacionais (Coleman et al., 1966; Cunha, 1975) e há consenso de que levantamentos educacionais não devem prescindir de medidas da origem social dos alunos. Desde 1995, o Saeb inclui medidas da educação dos pais ou responsáveis pelos alunos. Necessidade de enriquecimento das medidas socioeconômicas e dificuldades de obtenção de medidas da educação dos pais pelas respostas de alunos da 4a série levaram, com base no Saeb 99, à inclusão de medidas de indicadores de renda - via descrição de bens e serviços disponíveis nas residências dos alunos. No Saeb 2001 será incluído item que objetiva mensurar - ainda que com pergunta fechada - a ocupação dos pais ou responsáveis.

\section{Willms: indicadores-chave para o acompanhamento do sistema de ensino}

A proposta de avaliação de um sistema de ensino elaborada por Willms (1992) propõe um modelo que gera dados para responder quatro perguntas recorrentes em pesquisas sobre eficácia e equidade das escolas. São elas: 1 . até que ponto as escolas variam quanto a seus resultados?; 2 . até que ponto os resultados variam entre alunos de diferentes status?; 3. que políticas e práticas da escola contribuem para melhorar os níveis dos resultados escolares?; e 4. que políticas e práticas escolares contribuem para reduzir as desigualdades nos resultados entre grupos de alto e de baixo status? (op. cit, p. 120). Para este fim, Willms propõe um sistema de monitoramento baseado no modelo de "entrada-processo-saída". O pressuposto é que o resultado do aluno seria em grande parte determinado pelas influências da família e por sua trajetória escolar, os fatores de "entrada", e pelas experiências do aluno na escola, os fatores de "processos" moldados pelas práticas, políticas, estruturas organizacionais e normas da sala de aula, da escola e do distrito escolar. Com base em análise da literatura que focaliza questões de pesquisa relacionadas com suas quatro perguntas acima explicitadas, Willms (1992) identifica oito construtos particularmente relevantes para a avaliação de um sistema escolar. Esses construtos são apresentados no quadro 1. 


\section{Quadro 1 - Construtos propostos por Willms (1992) para a avaliação de sistemas escolares}

\begin{tabular}{|c|c|}
\hline Construtos & Descrição \\
\hline \multicolumn{2}{|l|}{ Escola: } \\
\hline Construtos de Ecologia e Meio & $\begin{array}{l}\text { Variáveis sobre infra-estrutura, recursos materiais, } \\
\text { característica do corpo docente e administrativo da } \\
\text { escola e composição dos estudantes. }\end{array}$ \\
\hline Segregação & $\begin{array}{l}\text { Variáveis indicadoras do grau de separação dos } \\
\text { alunos quanto status socioeconômico, etnia, raça, } \\
\text { capacidade, proficiência acadêmica, etc. }\end{array}$ \\
\hline Clima Disciplinar & $\begin{array}{l}\text { Diz respeito às regras de conduta na escola do ponto } \\
\text { de vista do professor, do aluno. }\end{array}$ \\
\hline Ênfase Acadêmica & $\begin{array}{l}\text { Valorização de resultados acadêmicos e altas } \\
\text { expectativas em relação aos alunos por parte do staff } \\
\text { acadêmico. }\end{array}$ \\
\hline $\begin{array}{l}\text { Currículo Projetado versus Currículo } \\
\text { Executado }\end{array}$ & $\begin{array}{l}\text { Variáveis que tentam captar o número de tópicos } \\
\text { relevantes a que os alunos foram expostos. }\end{array}$ \\
\hline \multicolumn{2}{|l|}{ Atitudes do Aluno: } \\
\hline Senso de eficácia versus futilidade & $\begin{array}{l}\text { Até que ponto os alunos acham que têm controle } \\
\text { sobre seu sucesso e suas falhas, se os professores se } \\
\text { preocupam com o seu progresso e se outros alunos os } \\
\text { punem se não logram sucesso. }\end{array}$ \\
\hline Atitudes em relação à escola & Satisfação dos alunos com sua escola. \\
\hline Qualidade da vida escolar & $\begin{array}{l}\text { Senso de bem-estar geral dos alunos, qualidade do } \\
\text { relacionamento aluno-aluno e aluno-professor, } \\
\text { comportamento acadêmico e planos de vida. }\end{array}$ \\
\hline \multicolumn{2}{|l|}{ Atitudes do Professor } \\
\hline Senso de eficácia versus futilidade & $\begin{array}{l}\text { Confiança do professor em sua capacidade de influir } \\
\text { na vida dos alunos e controlar o comportamento } \\
\text { deles. }\end{array}$ \\
\hline Compromisso e moral & $\begin{array}{l}\text { Até que ponto os professores consideram seu } \\
\text { trabalho como significativo e aceitam os objetivos e } \\
\text { valores organizacionais. }\end{array}$ \\
\hline Condições de trabalho & $\begin{array}{l}\text { Autonomia para realizar os objetivos da escola, } \\
\text { oportunidades de progresso profissional, tipo e } \\
\text { freqüência de avaliação, salários, tamanho de turma, } \\
\text { tempo disponível para atividades não-instrucionais, } \\
\text { alcance das decisões colegiais. }\end{array}$ \\
\hline Liderança do Diretor & $\begin{array}{l}\text { Variáveis que tentam captar a qualidade da liderança } \\
\text { administrativa da escola. }\end{array}$ \\
\hline
\end{tabular}


Willms reconhece que é difícil identificar e medir a maioria dos fatores associados aos processos escolares, pois muitos deles são complexos e multi-facetados e têm efeitos diferenciados dependendo do tipo de aluno ou do nível do sistema escolar. Não menos complexa é a definição da medida de resultados no modelo "entrada-processo-saída", pois isso depende da identificação dos objetivos da escola. Quase todas as escolas consideram que sua missão ultrapassa o objetivo de ensino de fundamentos das disciplinas básicas. Estes aspectos apenas sinalizam, na visão deste autor, alguns pontos de tensão envolvidos num sistema de avaliação. Perpassa por todo o seu texto um certo ceticismo que os resultados de monitoramento do sistema de ensino possam subsidiar soluções positivistas de políticas públicas.

\section{Lee, Bryk e Smith: a organização de uma escola secundária efetiva}

Lee, Bryk e Smith (1993) apresentam uma ampla revisão da literatura sobre a organização nas escolas secundárias bem sucedidas. Estão incluídos ensaios teóricos de cunho sociológico, historiográfico ou de psicologia social, estudos de caso em escolas específicas com abordagem etnográfica, pesquisas quantitativas e trabalhos anteriores de revisão.

Tal como Willms, estes autores fazem uma crítica aos modelos de análise que não consideram os processos escolares. A contribuição do trabalho é a proposição de um modelo conceitual heurístico da organização da escola secundária e suas influências não apenas em relação aos alunos, mas também a respeito dos professores e a conseqüente relação destes com aqueles. Os fatores escolares estão organizados em dois grandes grupos fatores externos e fatores internos - observando-se, por um lado, seus efeitos em relação ao grau de satisfação, eficiência, comprometimento e esforço dos professores e, por outro, o comprometimento e o desempenho dos alunos. Cada um dos grandes grupos de fatores contém vários construtos e subitens relacionados aos diversos níveis da organização escolar, conforme o quadro a seguir. 


\section{Quadro 2 - Construtos propostos por Lee, Bryk e Smith para estudos de avaliação de eficácia de escolas secundárias}

\section{Construtos e suas especificações}

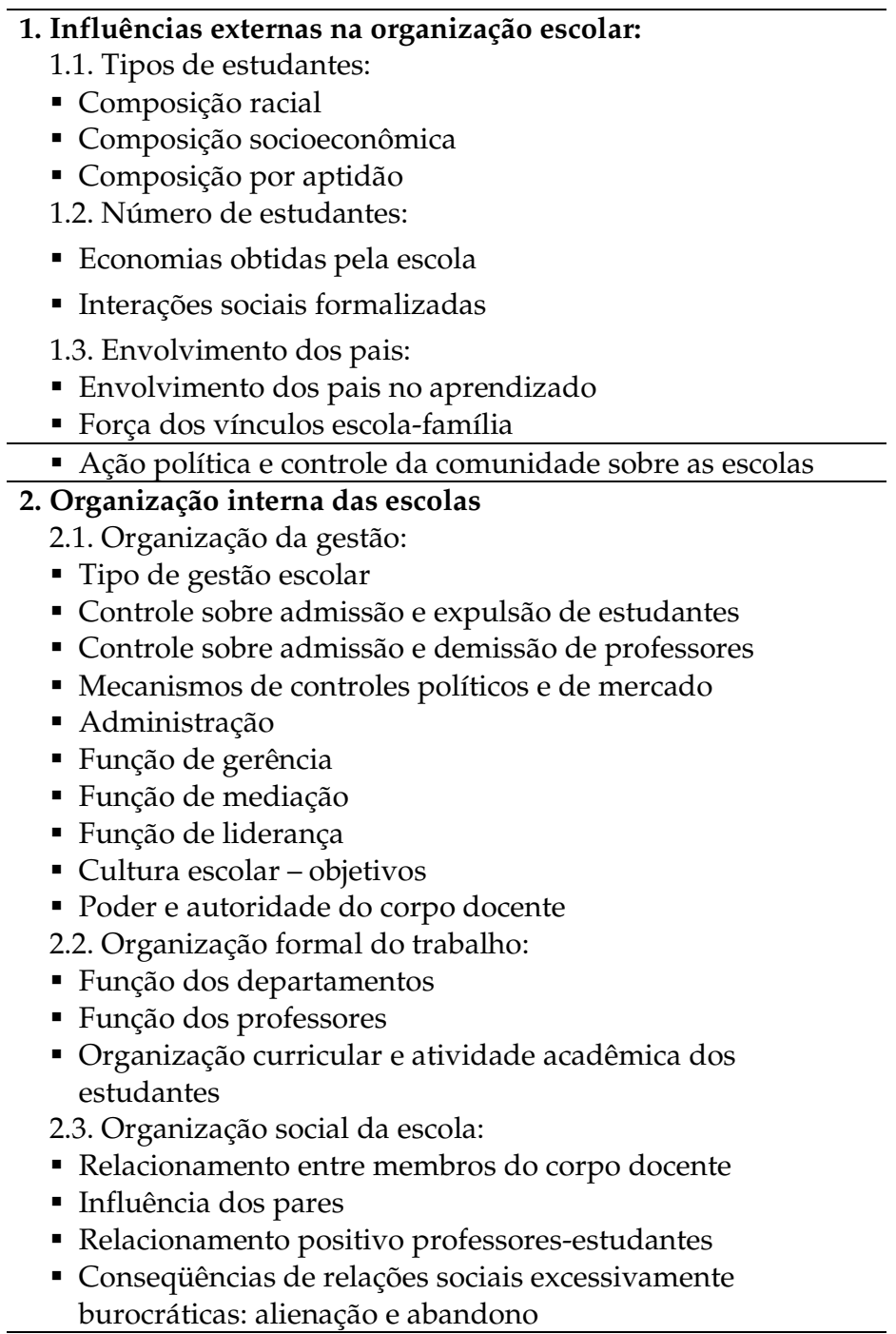

\section{Sammons, Hillman e Mortimore: onze características da escola efetiva}

Sammons, Hillman e Mortimore (1995) oferecem uma síntese da literatura sobre escola efetiva, a partir de estudos baseados em dados de diversos países, em especial do Reino Unido, dos Estados Unidos e da 
Holanda. Este trabalho focaliza as características que melhor descrevem escolas bem-sucedidas. A revisão concluiu que há pelo menos onze características presentes nas escolas que agregam valor aos seus alunos, sendo cada uma delas um construto que inclui alguns subitens. Estes onze fatores obtiveram uma grande repercussão e aparecem como referência em diversos trabalhos produzidos posteriormente. A lista não pretende ser exaustiva e os fatores não devem ser considerados independentes uns dos outros. Na verdade, há várias possibilidades de vínculos entre eles. Além disso, os autores enfatizam que se trata de características freqüentemente encontradas em escolas eficazes, o que não significa necessariamente que essas características possam ser diretamente implantadas em escolas pouco eficazes, ou que a eventual implantação direta dessas características em escolas pouco eficazes possam transformar essas escolas em escolas eficazes.

\section{Quadro 3 - Onze características encontradas em escolas eficazes, de acordo com Sammons, Hillman e Mortimore}

\begin{tabular}{|c|c|c|}
\hline 1 & Liderança profissional & $\begin{array}{l}\text { - firmeza e propósito } \\
\text { - uma abordagem participativa } \\
\text { - um diretor que exerça uma liderança profissional }\end{array}$ \\
\hline 2 & Visão e metas compartilhadas & $\begin{array}{l}\text { - unicidade nos propósitos } \\
\text { - prática consistente } \\
\text { - companheirismo e colaboração }\end{array}$ \\
\hline 3 & Um ambiente de aprendizado & $\begin{array}{l}\text { - uma atmosfera de organização } \\
\text { - um ambiente de trabalho atraente }\end{array}$ \\
\hline 4 & $\begin{array}{l}\text { Concentração no ensino e na } \\
\text { aprendizagem }\end{array}$ & $\begin{array}{l}\text { - maximização do tempo de aprendizado } \\
\text { - ênfase acadêmica } \\
\text { - foco centrado no desempenho }\end{array}$ \\
\hline 5 & Ensino com propósitos definidos & $\begin{array}{l}\text { - organização eficiente } \\
\text { - clareza nos propósitos } \\
\text { - lições estruturadas } \\
\text { - prática adaptável }\end{array}$ \\
\hline 6 & Altas expectativas & $\begin{array}{l}\text { - altas expectativas em todos os setores } \\
\text { - trocas e vocalização de expectativas } \\
\text { - ambiente intelectualmente desafiante }\end{array}$ \\
\hline 7 & Reforço positivo & $\begin{array}{l}\text { - regras de disciplina claras e consensuais } \\
\text { - retorno de informações a respeito das atividades de } \\
\text { alunos e professores }\end{array}$ \\
\hline 8 & Monitoramento do progresso & $\begin{array}{l}\text { - monitoramento do desempenho dos alunos } \\
\text { - avaliação do desempenho da escola }\end{array}$ \\
\hline 9 & $\begin{array}{l}\text { Direitos e responsabilidades dos } \\
\text { alunos }\end{array}$ & $\begin{array}{l}\text { - elevação da auto-estima dos alunos } \\
\text { - exigir responsabilidade dos alunos } \\
\text { - controle das suas atividades }\end{array}$ \\
\hline 10 & Relacionamento família-escola & - envolvimento dos pais no aprendizado das crianças \\
\hline 11 & $\begin{array}{l}\text { Uma organização orientada à } \\
\text { aprendizagem }\end{array}$ & $\begin{array}{l}\text { - desenvolvimento da equipe da escola com base nos } \\
\text { princípios e orientações desta. }\end{array}$ \\
\hline
\end{tabular}




\section{NCES: indicadores de qualidade da escola}

O relatório divulgado pelo National Center for Education Statistics (2000), do Departamento de Educação dos Estados Unidos, visa a responder a seguinte pergunta: por que algumas escolas são melhores do que outras na promoção do aprendizado do aluno? Com base na literatura sobre avaliação escolar, as bases de dados disponíveis sobre o tema e o exame crítico destes dados, o relatório sintetiza três grupos de indicadores fundamentais para a qualidade do ensino e da aprendizagem: o contexto escolar, os professores e o que ocorre na sala de aula. Cada um deles inclui alguns dimensões específicas, o que resulta em treze indicadores de qualidade da escola, conforme o quadro a seguir:

\section{Quadro 4 - Indicadores de qualidade da escola privilegiados em documento do US National Center for Educational Statistics}

\section{Indicador}

\section{Contexto Escolar:}

- Liderança profissional do diretor (aspectos administrativos e pedagógicos)

- Objetivos comuns da equipe (visões e crenças compartilhadas; clareza quanto aos objetivos da escola)

- Comunidade profissional (existência de colaboração entre os membros da equipe)

- Clima Disciplinar

- Ambiente acadêmico

Professores:

- Capacitação acadêmica do professor

- Especialização dos professores

- Experiência dos professores

- Desenvolvimento profissional

Sala de aula:

- Conteúdo das disciplinas (dos cursos)

- Método pedagógico

- Recursos tecnológicos

- Tamanho da turma

Uma contribuição importante deste trabalho é a análise da qualidade dos dados disponíveis para os três tipos de indicadores, como sugestão de temas de pesquisa que merecem estudos mais aprofundados. O relatório distingue dados com alta qualidade, referentes a dimensões relativamente simples, ou a dados que vêm sendo coletado sistematicamente por um longo período. Neste grupo, incluem-se os itens capacitação, especialização e experiência do professor e tamanho da turma. 
Há dados com qualidade moderada, em geral, quando as informações disponíveis acerca da dimensão são escassas. Desenvolvimento profissional do professor, recursos tecnológicos, conteúdo dos cursos, disciplina, ambiente acadêmico estão neste grupo intermediário. Finalmente, há dados de baixa qualidade que se referem a dimensões muito complexas. São eles, métodos pedagógicos, objetivos comuns, liderança profissional e comunidade profissional.

Em relação a este documento, vale ainda registrar a centralidade atribuída ao papel do professor para a qualidade da escola. O fator professor está associado, às vezes de forma indireta, com todos os treze indicadores.

\section{Guiomar Namo de Mello revisita o tema da escola eficaz}

Visando a contribuir para o debate sobre a avaliação institucional no Brasil, Mello (1994) faz um inventário de alguns trabalhos que sintetizam as características das escolas eficazes e chega a uma lista que inclui vários dos itens contemplados nas sínteses internacionais citadas anteriormente. Deixando transparecer uma certa doce de ironia nas entrelinhas, ela afirma que "a maioria dessas características faria parte das recomendações de educadores experientes em gestão escolar, ou mesmo de pessoas inteligentes e de bom senso". (p. 337). Mas, ao contrário do que possa parecer, Mello não se posiciona contra este tipo de síntese. Preocupada com a necessidade urgente de enfrentar a "catastrófica situação do ensino público entre nós" e romper com o pessimismo pedagógico que dominou as ciências sociais por décadas, ela valoriza justamente a necessidade de identificar e divulgar o conhecimento disponível a respeito da escola eficaz, naturalmente com uma leitura crítica em relação à realidade nacional. O alerta que ela nos faz é quanto à forma de utilização deste saber; o desafio não é descrever uma escola eficaz mas explicar o processo dinâmico pelo qual ela se desenvolve nessa direção. $\mathrm{O}$ terreno do "bom senso" sobre escolas eficazes esclarece, apenas parcialmente, o conteúdo da "caixa preta" que os modelos de "entradasaída" de desempenho escolar legaram às escolas. Se hoje já não há dúvidas que "a escola faz diferença", não há consenso a respeito do porquê da diferença, ou como criar esta diferença.

Mello conclui o seu trabalho com o argumento de que é nos limites das quatro paredes da sala de aula, em que se defrontam, no dia-a-dia, professores e alunos, que a idéia da escola como uma caixa preta ainda preserva o seu significado pleno. Com base em estudos internacionais que enfrentam esta tema de pesquisa, ela compartilha algumas questões acerca 
das práticas pedagógicas que são de interesse para o contexto brasileiro. As questões estão sintetizadas abaixo, a fim de contribuir para a reflexão proposta neste trabalho.

Quadro 5 - Fatores relevantes para a eficácia escolar de acordo com Mello (1994)

Fatores

\begin{tabular}{l}
\hline Importância do planejamento curricular (da escola) \\
Estrutura e organização curricular: disciplinas ou áreas de estudo? (gestão) \\
Domínio do conteúdo pelo professor (formação, experiência, capacitação continuada, \\
acompanhamento, supervisão) \\
Estratégia de organização da sala de aula (manejo balanceado de diferentes estratégias) \\
Método de ensino (Resultado de conhecimento, capacitação, condições de trabalho, \\
assistência técnica e esforço - competência e compromisso político)
\end{tabular}

\section{O documento "Referenciais para a formação de Professores"}

Em 1998 a Secretaria de Educação Fundamental do Ministério da Educação e do Desporto produziu o documento "Referenciais para Formação de Professores" (MEC, 1998), síntese de uma amplo trabalho de discussão que envolveu profissionais da educação de diversas filiações institucionais. O documento refere-se basicamente à formação de professores de Educação Infantil e dos primeiros quatro anos do Ensino Fundamental. O debate que orientou a produção destes referenciais foi contextualizado, como não poderia deixar de ser, com base em uma discussão mais ampla sobre a educação escolar, as condições necessárias para assegurar uma educação de qualidade e sobre o papel da escola e do professor. A partir dessas reflexões, chegou-se a um consenso a respeito de quais são as condições necessárias para assegurar uma educação escolar de qualidade real.

Os itens deste consenso são bastante significativos para os objetivos deste trabalho. Pode-se estabelecer alguns paralelos com as reflexões alhures, mas certamente esta síntese, mesmo tendo sido produzida com outros objetivos, é importante porque traz aspectos tangíveis ao contexto nacional. 


\section{Quadro 6 - Os fatores de qualidade da escola privilegiados pelos referenciais para formação do professor (MEC, 1998)}

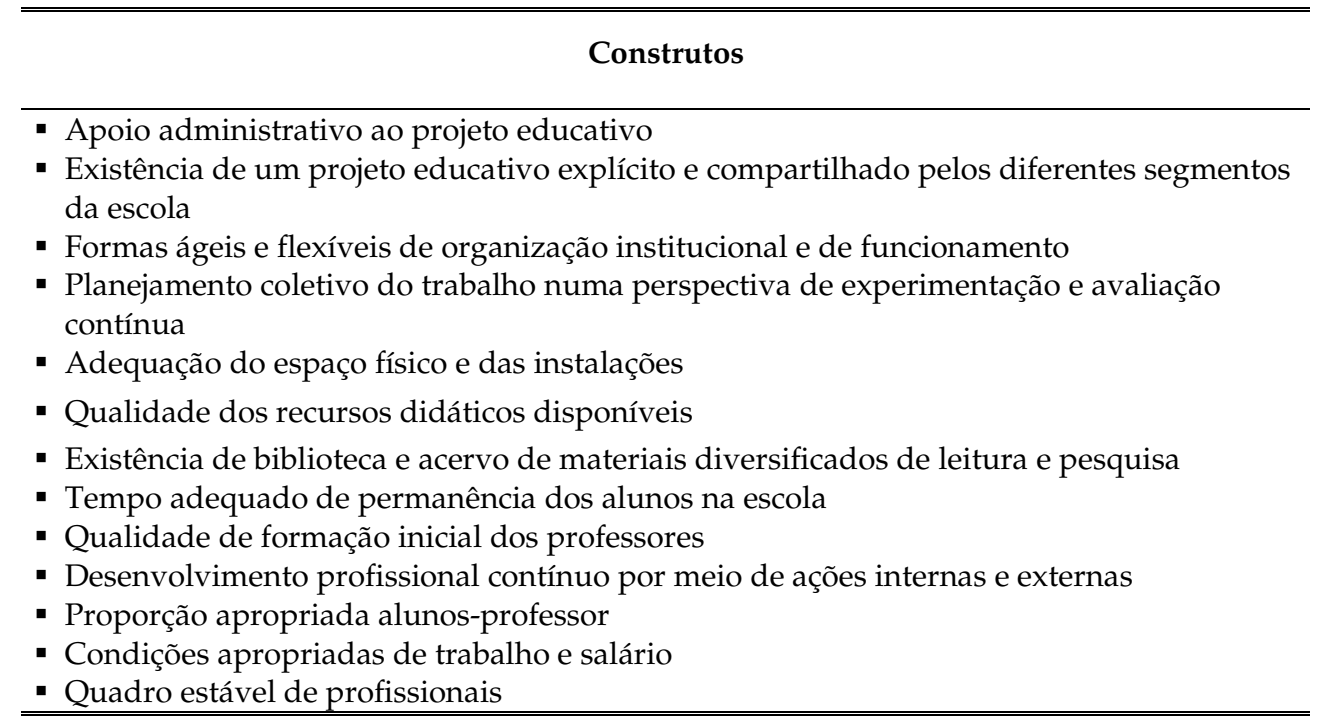

\section{SÍNTESES A PARTIR DE ANÁLISES DOS DADOS DO SAEB E DO SARESP}

Alguns trabalhos recentes incorporam às análises dos dados do Saeb a reflexão sobre o desempenho do aluno e a escola eficaz. Destacam-se os trabalhos produzidos por Barbosa e Fernandes (2001) e Soares et al. (2001) com base nos dados do Saeb-1997, os relatórios técnicos não publicados de análise dos dados do Saeb-1999 de Soares et al. (2000) e Barbosa et al. (2001).

Também merece registro o trabalho de Soares et al. (2000, mimeo) que produz uma importante sistematização da literatura a respeito da avaliação educacional e escola eficaz e estabelece uma comparação original entre os fatores relevantes associados à escola e ao aluno e sua família segundo o referencial teórico e os fatores presentes nos questionários do Saeb-1997. Há neste trabalho um grande esforço para a construção de índices que são tomados como fatores explicativos da proficiência do aluno. Com relação ao ciclo de avaliação de 1999, Soares et al. reúnem os fatores explicativos construídos a posteriori com base nos itens dos questionários em três grupos: fatores de caracterização do aluno, do diretor e do professor - os discriminantes de cada um -; fatores de entrada (inputs) - as caraterísticas que não são modificáveis através de políticas e práticas intraescola; e os fatores de processo - as práticas internas das escolas ou que são 
diretamente influenciadas por elas. O objetivo é esclarecer no modelo explicativo o peso de cada possível tipo de intervenção política na escola.

No conjunto destes trabalhos fica bastante evidente a importância do referencial teórico proposto pela literatura especializada, mas a necessidade de incorporação de questões específicas sobre a realidade nacional. A este respeito, Barbosa e Fernandes (2001) mostram que grande parte da variabilidade existente entre escolas da região Sudeste onde se ministra a $4^{a}$ série se deve a condições de infra-estrutura e equipamento.

Igualmente, Barbosa et al. (2001) mostraram que as condições físicas e ambiente da escola são variáveis que impactam a proficiência em qualquer das 5 grandes regiões do país. Este estudo mostra ainda que há uma forte correlação entre as condições de infra-estrutura e equipamento das escolas e o nível socioeconômico da população abrangida em cada uma delas.

A literatura internacional não menciona o fator "condições de infraestrutura e equipamento" como sendo determinante dos resultados escolares. Porém, tanto Peter Mortimore quanto John Gray referem-se ao assunto. Mortimore et al. (1988) menciona que as escolas que constituem a sua amostra:

"Como todas as escolas [na região investigada] encontravam-se em boas condições em termos de recursos, constatamos que isso não era um fator chave [para a eficácia escolar]. Se nossa amostra fosse composta de escolas provenientes de autoridades educacionais locais que tivessem tradições diferenciadas em termos de investimentos em recursos educacionais, seria improvável que este resultado fosse encontrado." (p. 264)

Ainda a respeito dos recursos escolares disponíveis, Gray (1990, p. 213) observa que níveis adequados de recursos parece ser uma condição necessária mas não suficiente para a eficácia da escola.

Franco, Mandarino e Ortigão (2002) investigaram o efeito da existência de plano pedagógico da escola tanto na eficácia da escola quanto da equidade promovida pelas escolas. Esses autores reportaram que o planejamento pedagógico da escola tem efeito nos resultados escolares: os alunos de escolas que possuem plano pedagógico têm melhores resultados e, dentro de cada escola, alunos de nível socioeconômico baixo, médio e alto são beneficiados pela existência do plano de escola, mas os alunos de nível socioeconômico mais elevado são os que mais se beneficiam dos planos de escola.

Espósito, Davis e Nunes (2000) investigaram fatores explicativos de eficácia escolar em Língua Portuguesa dos alunos que tinham acabado o ensino fundamental e ingressado no ensino médio. As autoras reportaram 
efeitos associados a trabalho colaborativo da equipe de professores, ao comprometimento dos professores com o resultados de seus alunos e à freqüência de utilização do laboratório de ciências. Os dois primeiros resultados reportados estão sintonizados com outros resultados apresentados em pesquisas internacionais (Lee, 2001; Sammons, Hillman, Mortimore, 1995). Já o efeito do laboratório de ciências no resultado em Língua Portuguesa é de mais difícil interpretação. Talvez a variável explicativa tenha capturado tendências gerais da escola relacionadas com inovação e qualidade de ensino, que assumem um caráter mais explícito na área de ciências, com o uso freqüente do laboratório, mas que estejam presentes de modo mais sutil - e não captada diretamente pelos instrumentos - na área de Língua Portuguesa.

A Fundação Carlos Chagas - FCC (2001) identificou 10 escolas públicas brasileiras em que a proficiência dos alunos era elevada quando comparada com outras escolas com clientela de nível socioeconômico similar. Em seguida, esses autores conduziram pesquisa qualitativa nessas escolas e registraram que elas contavam com professores altamente motivados, desenvolviam ênfase na aprendizagem acadêmica e possuíam diretores que atuavam como efetiva liderança. Os autores relataram ainda, não sem expressar que o assunto precisa ainda ser melhor investigado, que o estilo de liderança dos diretores era mais voltado para a resolução dos problemas operacionais da escola e de sua equipe de professores do que para os aspectos estritamente pedagógico do funcionamento da escola.

\section{OS CONSTRUTOS PRIVILEGIADOS PELOS INSTRUMENTOS DO SAEB 2001}

Apresentamos e discutimos abaixo os construtos privilegiados pelos questionários do Saeb. A apresentação guarda relação com a divisão dos questionários: do aluno, do professor, da turma, do diretor e da escola. Note-se que o questionário da turma e da escola é respondido pelo membro externo responsável pela operacionalização do Saeb em cada escola.

\section{Os construtos relacionados com o aluno}

Os construtos relacionados aos alunos cumprem duas funções em avaliações de sistemas educacionais: permitir que a pesquisa aborde questões relativas à equidade; e oferecer controles adicionais para a investigação de fatores escolares que promovem eficácia escolar. O 
tratamento do tema da eqüidade impõe a necessidade de coleta de dados relacionados a fatores sociais, econômicos e demográficos. Além desses, é relevante que se mensure outras características dos alunos e suas famílias que estejam relacionadas com o desempenho educacional. A razão para isso é a de evitar que análises encontrem como fatores promotores da eficácia escolar variáveis que estão apenas associadas a características individuais que promovem aprendizagem. Os questionários do Saeb 2001 buscam captar informações e mensurar os construtos que estão listados no quadro 7, que indica ainda o detalhamento dos construtos. Versão completa dos questionários estão disponíveis em Inep (2001).

\section{Quadro 7: Os construtos relacionados ao aluno}

\begin{tabular}{|l|l|}
\hline \multicolumn{1}{|c|}{ Construto } & \multicolumn{1}{c|}{ Especificação } \\
\hline $\begin{array}{l}\text { Caracterização } \\
\text { sóciodemográfica }\end{array}$ & $\begin{array}{l}\text { Idade } \\
\text { Escolaridade dos pais ou dos } \\
\text { responsáveis } \\
\text { Indicadores de renda } \\
\text { Estrutura familiar } \\
\text { Gênero } \\
\text { Cor declarada }\end{array}$ \\
\hline Capital social & $\begin{array}{l}\text { Envolvimento da família com a escola; } \\
\text { Relação família com aluno } \\
\text { Apoio social recebido via escola }\end{array}$ \\
\hline Capital cultural & Recursos culturais disponíveis em casa \\
\hline Motivação e auto-estima & Motivação e auto-estima \\
\hline Práticas de estudo & Dever de casa \\
\hline Trajetória escolar & Miscelânea \\
\hline
\end{tabular}

Nos modelos explicativos da proficiência no Saeb, os construtos do aluno incluem características individuais do aluno à entrada na escola que são fundamentais para o controle estatístico dos fatores associados às escolas. A inclusão das chamadas covariáveis específicas para os alunos tem por objetivo criar, através de modelo estatístico, comparabilidade entre os alunos das diferentes escolas, ou seja, a equalização do alunado das diferentes escolas. Idealmente, para estimar o efeito-escola, a modelagem deveria contar também com a informação sobre o nível de conhecimento prévio do aluno obtido em uma avaliação padronizada anterior. No 
entanto, o Saeb, sendo um estudo transversal e não longitudinal, não o permite. Diante deste tipo de limitações, Barbosa et al. (2001) definem:

"Escola-eficaz, em sentido lato, é o modelo de escola que, apesar de não ter existência física, tem configuração desenhada a partir das características comuns às escolas do sistema onde os alunos atingem melhor desempenho em contraponto com as características das escolas onde os alunos apresentam piores resultados." (p. 5)

Estes autores pressupõem ainda que o conhecimento prévio do aluno à entrada na escola está fortemente correlacionado com o seu nível socioeconômico. O estudo mencionado dá prioridade à análise e modelagem dos dados da $4^{\text {a }}$. série por quatro motivos:

1) é aquela onde a falta de controles adequados é minimizada;

2) há evidências, com base na literatura internacional, de que o ensino fundamental tem efeito de longo prazo no percurso escolar dos alunos;

3) as escolas de $4^{\text {a }}$. série servem a população de mais largo espectro comparativamente às demais.

Os construtos a serem medidos em cada aluno, definidos a partir das referências analisadas no item 5 e das especificidades do Saeb, são: caracterização do aluno, capital econômico, capital cultural, capital social, motivação e auto-estima, esforço acadêmico, apoio familiar e controle da trajetória escolar.

Alguns comentários sobre os construtos do nível aluno.

A caracterização do aluno são os discriminantes individuais que permitem a divisão dos alunos em subgrupos com importância teórica e descritiva. Os principais são sexo, idade, cor e estrutura familiar (com quem mora).

O capital econômico, o capital cultural e o capital social são dimensões do status socioeconômico do grupo familiar do aluno.

O capital econômico, usualmente, é mensurado por meio da riqueza da família, aferida diretamente pela renda familiar ou estimada através da ocupação dos pais ou responsáveis pelo núcleo familiar. No entanto, há dificuldades, no momento incontornáveis, para se obter essas informações. Em relação à renda familiar, não se recomenda perguntá-la diretamente devido à enorme probabilidade de não-respostas ou de respostas inconsistentes. Esta é uma informação com margem considerável de imprecisão em qualquer circunstância de pesquisa, mais ainda junto a uma amostra de alunos, a maioria crianças e adolescentes. A estimação da 
riqueza familiar através da ocupação é a alternativa adotada pelo PISA ${ }^{1}$, por exemplo. Especificamente para a realidade brasileira, há um estudo de Pastore, Silva (2000) que estabelece uma classificação de posição socioeconômica pela combinação de rendimento individual e o nível educacional dentro de cada título ocupacional da Classificação Brasileira de Ocupações (CBO), com base nos dados do PNAD de 1996. A classificação final em seis estratos poderia ser uma base para a validação da classificação das ocupações dos pais dos alunos, sem a necessidade de se perguntar diretamente a renda familiar. No entanto, esta opção esbarra no planejamento do Saeb, que não prevê a codificação de respostas abertas. Perguntar o setor da ocupação (indústria, comércio, serviços, etc.) não substitui a informação sobre ocupação porque isso não permite uma classificação hierárquica

Alternativamente, para compor o capital econômico, trabalha-se com a classificação econômica obtida pela posse de itens de conforto dos lares dos alunos, o Critério Brasil da ABA/ANEP 2, e as condições da moradia quanto ao conforto (número de quartos e outros cômodos) e o acesso a recursos de urbanização pública (calçamento, iluminação e água encanada).

O Critério de Classificação Econômica Brasil tem por objetivo responder às demandas do mercado interessado em estimar o poder de compra das pessoas e famílias urbanas. As perguntas para compô-lo são simples e diretas, à exceção da escolaridade do chefe da família (ou dos pais), que pode ser desconhecida para muitos alunos da $4^{\text {a }}$ série, como ocorreu no Saeb-99, quando cerca de 30\% destes não souberam declarar a escolaridade dos pais ${ }^{3}$. O problema em relação a esta classificação é que, isoladamente, ela resulta em categorias limitadas para a análise de dados educacionais. Experiências de uso têm mostrado que o Critério Brasil não consegue discriminar setores de renda muito baixa. A inclusão de itens sobre as condições do domicílio visa a oferecer uma alternativa de discriminação dos setores mais carentes de capital econômico.

\footnotetext{
1 O PISA (Programme for International Student Assessment) é sistema de avaliação conduzido pelos países OECD com estudantes de 15 anos de idade. Em 2000, o estudo envolveu 32 países.

2 Associação Brasileira de Anunciantes e Associação Nacional de Empresas de Pesquisa de Mercado. A ABIPEME (Associação Brasileira dos Institutos de Pesquisa de Mercado) concorda com o Critério Brasil, mas mantém a sua própria classificação, que, em linhas gerais, é bastante parecida com esta. Fonte: Revista Brasileira de Pesquisa de Mercado. Ano 1, n. ${ }^{\circ}$ 2, agosto/1997, p. 26-32.

3 Para não perder os casos normalmente o item é estimado através de modelo de regressão, no qual os itens presentes são usados como fatores explicativos.
} 
O capital cultural é um conceito incorporado aos estudos educacionais com base nos estudos de Bourdieu sobre reprodução social. O capital cultural se relaciona aos valores, às formas de comunicação e aos padrões de organização das classes dominantes. Ter capital cultural significa possuir competência lingüística e social para traduzir os códigos culturais de mais alto nível. No setor educacional, em geral, as instituições de ensino tomam como referência o capital cultural assim entendido. Mas, como mostra Lareau (1987), desde que o conceito de capital cultural foi introduzido, diferentes interpretações têm sido feitas. Esta autora o define como os bens culturais que são transmitidos pelas diferentes ações pedagógicas familiares. O capital cultural mede o clima educacional da família através de hábitos culturais, hábitos de leitura, freqüência ao cinema e teatro, assiduidade na frente da televisão, entre outros, que definem um ambiente mais favorável ou não para as realizações educativas.

Não há consenso acerca da melhor forma de medir este construto. Silva e Hasenbalg (2000), em estudo sobre educação no Brasil, utilizam a educação materna como indicador do capital cultural. Willms (1998) recomenda que o capital cultural inclua itens sobre a participação familiar em atividades culturais. Porém, se por um lado a opção de Silva e Hasenbalg é muito restrita, por outro, a recomendação de Willms esbarra na realidade nacional, que dispõe de muito poucos recursos culturais (cinemas, teatros, museus, livrarias) em grande parte dos municípios brasileiros.

Para compor a medida de capital cultural os questionários do aluno incluem a escolaridade dos pais ou responsáveis, a quantidade de livros disponíveis na casa do aluno, materiais de leitura disponíveis (jornal diário, revista semanal, enciclopédia, etc.) e hábitos de leitura do aluno. Estas informações tangenciam o construto capital cultural, mas nos parece a melhor aproximação dada a dificuldade de incluí-la em um estudo com características macro como é o Saeb.

A referência básica do capital social encontra-se em Coleman (op. cit.). O conceito aparece nos trabalhos de Willms e de Silva e Hasenbalg, citados anteriormente. O capital social é definido pela quantidade de vínculos sociais que o indivíduo pode contar no lugar onde vive para facilitar a sua ação dentro da estrutura social. O capital social reside, basicamente, na relação entre as pessoas. $\mathrm{Na}$ família, este conceito é traduzido nas relações entre pais e filhos, na quantidade e na qualidade de tempo que os pais despendem com os filhos. Teachman et al., 1997 (citado por Silva, Hasenbalg, op. cit.) em estudo acerca do efeito dos vários "capitais" na continuidade dos estudos, concluíram que o capital social é o 
filtro através do qual o capital econômico e o capital cultural são convertidos em fatores de desempenho escolar.

Os questionários propostos para o Saeb 2001 incluem questões sobre a estrutura familiar (discrimante), tipos de contatos estabelecidos entre pais e filhos e número de vezes que o aluno já mudou de escola. Este último item, relacionado também à trajetória escolar do aluno, indica a permanência dos vínculos sociais estabelecidos na comunidade escolar.

A motivação e a auto-estima do aluno são construtos intrinsecamente relacionados e de difícil mensuração. São atributos subjetivos e podem estar associados ao aluno, quando este traz consigo altas expectativas no que se refere à sua própria aprendizagem e ao seu futuro profissional, demostra confiança em si mesmo e tem um sentimento de aprovação social ou podem ser fruto de processo desencadeado na escola, através do professor ou outros fatores, que conseguem motivar e desenvolver a auto-estima dos alunos com o projeto educacional.

Em Willms (1992), a motivação é compreendida como "o senso de eficácia versus o senso de futilidade acadêmica" associada ao aluno e ao professor. É uma medida do engajamento do estudante e do seu mestre com a escola. Neste esquema, o construto faz parte dos processos escolares. Para apreendê-lo, são construídas escalas compostas por inúmeros itens com o objetivo de captar as várias dimensões da motivação do aluno.

No Estudo Exploratório desenvolvido pela FCC no âmbito do Saeb 99 para investigar os fatores psicossociais associados ao processo escolar, a auto-estima dos alunos, como uma dimensão importante da competência dos alunos, foi o foco da análise. Para captá-la, foram construídos questionários compostos por 30 questões, cujas alternativas de respostas dicotômicas indicavam ou auto-estima mais positiva ou mais negativa.

Os questionários dos alunos incluem itens acerca da motivação instrumental (expectativa quanto ao futuro entre continuar estudando ou trabalhar) e a motivação para as disciplinas avaliadas. No entanto, para captar todas as dimensões envolvidas no construto é necessário estudos mais complexos, que incluam escalas de motivação e escalas de autoestima.

O esforço acadêmico tem muita correlação com a motivação, na medida em que é uma tradução prática da mesma. Nos questionários do aluno este construto é medido pelo hábito de fazer lição de casa e pela atitude do aluno frente às dúvidas com a matéria.

O apoio familiar é um dos principais fatores do processo de aprendizagem do aluno. Por exemplo, Willms (no prelo) analisou dados sobre o envolvimento dos pais em cerca de 1000 escolas que participaram do U.S.National Educational Longitudinal Study e encontrou fortes evidências 
sobre o efeito global positivo do envolvimento dos pais na escola dos filhos acerca do desempenho acadêmico destes.

São vários os indicadores do envolvimento dos pais, no âmbito da família ou na escola. Mais diretamente ligadas ao contexto familiar, são identificadas as atitudes dos pais em relação às atividades escolares, como o monitoramento do dever de casa, o apoio nas atividades escolares e o conhecimento do desempenho do filho. Os questionários do aluno incluem itens para compor este construto.

A trajetória escolar é um construto cuja relevância justifica-se sobretudo pelas especificidades da realidade nacional, tal como é revelada, por exemplo, pelos dados do próprio Saeb. O fracasso escolar, a evasão e a distorção idade/série são fatores com altas taxas de incidência nas escolas do país, sobretudo as públicas, com reflexo direto no rendimento do aluno. Os questionários do aluno incluem itens sobre repetência e abandono da escola. Além disso, a variável idade revela a adequação da idade/série do aluno.

\section{Os Construtos relacionados com a sala de aula}

O papel desempenhado pelo professor no aprendizado de seus alunos é fundamental e a mensuração de características do professor é um componente bastante importante de surveys educacionais. Por isso mesmo, será importante explicitar as limitações de análises de surveys educacionais em dar conta da influência do professor na aprendizagem de seus alunos. Em pesquisas como o Saeb, em que a proficiência dos alunos é mensurada uma única vez, a proficiência do aluno é uma medida de seu aprendizado ao longo de sua vida. Por isso, a explicação dessa proficiência em função de características da escola por ele freqüentada no último ano deve ser interpretada com cautela. Mais cautela ainda é recomendada para análises envolvendo dados dos professores, cujos estilos e características podem ser bastante distintos mesmo em uma mesma escola. Em princípio, a situação pareceria mais promissora no âmbito de pesquisas que envolvessem medidas de proficiência a cada ano. Nesse desenho de pesquisa, seria possível obter medida do aprendizado em um ano letivo e, eventualmente, associar esse aprendizado às características de um professor. Ainda que o desenho de pesquisa que mensura a proficiência dos alunos mais de uma vez tenha claras vantagens em relação aos estudos que mensuram a proficiência uma única vez, é importante sublinhar que, quase sempre, os artigos publicados baseiam-se em aprendizado ao longo de ao menos dois anos letivos, o que acaba por impor limitações à investigação do efeito 
professor. A principal dificuldade em conduzir estudos envolvendo aprendizagem em um único ano letivo é a alta correlação entre as duas medidas de proficiência, o que reduz drasticamente a variância a ser explicada. No entanto, há duas razões que estimulam a mensuração de características associadas ao professor: a existência de diferenças muito marcantes entre a formação de professores que ensinam a diferentes grupos de alunos; a possibilidade de captar fatores escolares com base no questionário dos professores. Esses últimos fatores estão reportados mais adiante, junto com os construtos da escola.

Quadro 8 - Os construtos relacionados à sala de aula

\begin{tabular}{|c|c|}
\hline Construto & Especificação \\
\hline $\begin{array}{l}\text { Caracterização } \\
\text { sociodemográfica } \\
\text { do professor }\end{array}$ & $\begin{array}{l}\text { Idade } \\
\text { Renda } \\
\text { Etnia } \\
\text { Gênero } \\
\text { Educação }\end{array}$ \\
\hline $\begin{array}{l}\text { Formação do } \\
\text { Professor }\end{array}$ & $\begin{array}{l}\text { Nível da Formação inicial } \\
\text { Caracterização da instituição formadora } \\
\text { Pós-graduação } \\
\text { Formação continuada }\end{array}$ \\
\hline $\begin{array}{l}\text { Experiência } \\
\text { Profissional }\end{array}$ & $\begin{array}{l}\text { Anos de formação } \\
\text { Anos como professor } \\
\text { Ano como professor da disciplina lecionada } \\
\text { Anos na escola }\end{array}$ \\
\hline $\begin{array}{l}\text { Condições de } \\
\text { trabalho }\end{array}$ & $\begin{array}{l}\text { Salário como professor } \\
\text { Satisfação com salário } \\
\text { Exercício de outra atividade remunerada } \\
\text { Número de escolas em que trabalha } \\
\text { Número de horas semanais em sala de aula }\end{array}$ \\
\hline Estilo pedagógico & $\begin{array}{l}\text { Dever de casa } \\
\text { Ênfase em raciocínio abstrato, em contextua- } \\
\text { lização e/ou em automatização (matemática) } \\
\text { Ou ênfase em ensino da língua via diversidade } \\
\text { textual, em contextualização e/ou em } \\
\text { automatização (língua portuguesa) } \\
\text { Posturas relacionadas com a avaliação }\end{array}$ \\
\hline Expectativa & $\begin{array}{l}\text { Expectativa do professor referente à conclusão } \\
\text { do EF (ou do EM) }\end{array}$ \\
\hline Miscelânea & $\begin{array}{l}\text { Presença e rotatividade de professor } \\
\text { Turno }\end{array}$ \\
\hline
\end{tabular}


O conjunto de fatores apresentados na literatura revista nas seções anteriores apresentam resultados convergentes com a literatura qualitativa contemporânea acerca do saber docente. Foram particularmente relevantes para nós os trabalhos de Gauthier (1998), de Tardiff, Lessard, Lahaye (1991) e de Tardiff, Lessard (1999), autores que discutem os saberes que estão na base da prática pedagógica de professores. Mais especificamente, os conceitos de saber da experiência e saber da ação pedagógica permitiramnos, simultaneamente, ampliar a noção de formação para além da formação inicial e das iniciativas formalizadas de formação continuada de professores - incluindo, portanto, as interações dos professores em seu ambiente profissional de trabalho - e restringir a noção de formação àquilo que envolve a socialização profissional de professores, excluindo, portanto, aspectos relacionados à história de vida dos professores. Os trabalhos dos autores mencionados vêm tendo grande repercussão na pesquisa educacional brasileira e diversos autores têm enfatizado a pertinência de uma visão ampliada da origem do repertório de saberes dos professores (Queiróz, 2001) e sublinhado a relevância da escola como instância de formação continuada de professores (Nascimento, 1997; Franco, Sztajn 1999). As convergências entre os artigos de revisão por nós já apresentados e a investigação acerca do saber docente nos levaram ao conjunto de construtos priorizados no quadro acima, que se relacionam com os saberes disciplinares, curriculares, das ciências da educação, da tradição pedagógica, da experiência e da ação pedagógica (Gauthier, 1998). Além disso, priorizamos a obtenção de informações capazes de oferecer uma breve caracterização sociodemográfica do professor.

Os construtos relacionados ao professor estão intimamente associados à turma testada para a qual esse professor estuda. No âmbito do Saeb há um pequeno questionário de turma preenchido pelo agente externo responsável pela aplicação do Saeb na escola. Esse questionário envolve alguns itens relativos especificamente às turmas testadas e alguns de seus itens já foram incluídos no quadro 8 , enquanto outros serão incluídos no quadro 9.

\section{Construtos relacionados à Escola}

Os construtos relacionados à escola serão captados pelos questionário do diretor, da escola e do professor. O quadro 9 apresenta os contrutos privilegiados. 


\section{Quadro 9: Os construtos relacionados à escola}

\begin{tabular}{|c|c|}
\hline Construto & Especificação \\
\hline $\begin{array}{l}\text { Caracterização } \\
\text { sociodemográfica do } \\
\text { diretor }\end{array}$ & $\begin{array}{l}\text { Idade } \\
\text { Renda } \\
\text { Etnia } \\
\text { Educação }\end{array}$ \\
\hline Formação do diretor & $\begin{array}{l}\text { Nível da formação inicial } \\
\text { Caracterização da instituição de formação } \\
\text { Pós-graduação } \\
\text { Formação continuada }\end{array}$ \\
\hline Experiência do diretor & $\begin{array}{l}\text { Tempo de trabalho em educação } \\
\text { Tempo como diretor } \\
\text { Tempo como diretor da escola }\end{array}$ \\
\hline Liderança & Liderança do diretor \\
\hline $\begin{array}{l}\text { Condições de trabalho } \\
\text { do diretor e da equipe }\end{array}$ & $\begin{array}{l}\text { Carências da escola } \\
\text { Forma de escolha do diretor } \\
\text { Carga horária do diretor } \\
\text { Direção: apoios e interferências } \\
\end{array}$ \\
\hline Trabalho colaborativo & $\begin{array}{l}\text { Colaboração entre membros do corpo docente } \\
\text { Instâncias de gestão da escola } \\
\text { Estabilidade ou rotatividade do corpo docente }\end{array}$ \\
\hline $\begin{array}{l}\text { Organização do ensino } \\
\text { e políticas de promoção }\end{array}$ & $\begin{array}{l}\text { Ciclos e sua duração } \\
\text { Políticas para minoração de repetência e abandono }\end{array}$ \\
\hline Clima acadêmico & $\begin{array}{l}\text { Comprometimento da equipe com ensino e com } \\
\text { aprendizagem } \\
\text { Atitudes frente ao absenteísmo } \\
\text { Existência de "cantinho de livros" e de murais } \\
\text { expressivos (só p/ } 4^{\text {a }} \text { série) } \\
\text { Organização de atividades voltadas para a } \\
\text { recuperação da aprendizagem } \\
\text { Existência e utilização da biblioteca }\end{array}$ \\
\hline Clima Disciplinar & Aspectos do clima disciplinar \\
\hline Recursos pedagógicos & Recursos pedagógicos \\
\hline $\begin{array}{l}\text { Situação das instalações } \\
\text { e equipamentos }\end{array}$ & $\begin{array}{l}\text { Estado de conservação do prédio } \\
\text { Aspectos ambientais } \\
\text { Limpeza } \\
\text { Segurança das instalações } \\
\text { Existência e estado de recursos s pedagógicos } \\
\text { Situação geral da infra-estrutura } \\
\end{array}$ \\
\hline $\begin{array}{l}\text { Atividades } \\
\text { extracurriculares }\end{array}$ & \begin{tabular}{|l|} 
Voltadas para alunos \\
Voltadas para a comunidade \\
\end{tabular} \\
\hline Miscelânea & $\begin{array}{l}\text { Admissão de alunos } \\
\text { Critérios de formação de turmas } \\
\text { Critérios de atribuição de professores para as } \\
\text { turmas } \\
\text { Oferecimento de programas direcionados a alunos } \\
\text { com necessidades especiais } \\
\text { Acesso aos resultados do Saeb }\end{array}$ \\
\hline
\end{tabular}


A priorização dos construtos relacionados com a direção foi derivada tanto da revisão das pesquisas internacionais quanto da pesquisa qualitativa conduzida pela Fundação Carlos Chagas (2000) em escolas incluídas na amostra do Saeb 99. Ainda que haja razões para associar 'boa gestão' com bom rendimento escolar (Gray, 1990), a literatura tem destacado que o sentido da liderança que faz a diferença e as razões para a diferença são bem menos claros (Bryk, Camburn, Louis 1999). A maior parte da literatura educacional ressalta a relevância do papel pedagógico do diretor, o que não impediu que o estudo qualitativo conduzido pela Fundação Carlos Chagas (2000) enfatizasse o achado de que diretores de escolas eficazes atuavam para garantir o bom funcionamento administrativo das escolas e as condições administrativas para o bom trabalho de seus professores. Já para o contexto francês, Bressoux (1994) sugere que o papel do diretor da escola eficaz pode variar segundo a composição socioeconômica da escola: em escolas menos afluentes o papel seria o de líder e nas mais afluentes a de um gerente capacitado. Os construtos privilegiados incluíram a formação e experiência do diretor e seu estilo de gestão - aí incluídas as instâncias de direção existentes e em funcionamento e a atuação do diretor visando o desenvolvimento profissional dos professores. Analogamente ao caso do professor, será feita uma breve caraterização sociodemográfica do diretor. O tema da liderança do diretor e sua atuação facilitadora do trabalho docente é também priorizada e abordada via questionário dos professores.

A revisão de literatura já tinha assinalado a importância do trabalho colaborativo dos professores como um importante fator associado à eficácia da escola. Trabalhos recentes reforçam esses achados e registram a relevância do trabalho colaborativo para a promoção de equidade pela escola (Lee, 2001; Bryk, Camburn, Louis 1999). Construtos relacionados com colaboração bem como com ênfase acadêmica e clima disciplinar da escola foram priorizados pelos questionários.

Em face dos resultados já reportados de análises com base em dados do Saeb, os questionários propostos do Saeb 2001 contemplam construtos relacionados aos recursos pedagógicos disponíveis, à utilização da biblioteca, à conservação das instalações e às condições de segurança da escola.

\section{CONSIDERAÇÕES FINAIS}

Este quadro de referencial conceitual não pretende afirmar que os instrumentos conceituais do Saeb estão finalizados e devem ser mantidos 
do modo como estão apresentados no anexo a este documento. Ao contrário, reconhecemos que os instrumentos são fruto de uma leitura - a melhor que foi possível desenvolver nas presentes condições - da literatura relevante, da situação educacional brasileira e das características do próprio Saeb. Espera-se que a própria divulgação deste documento enseje reflexões que possam redundar em propostas de constante aprimoramento dos instrumentos do Saeb. Além disso, mudanças na situação educacional, a disponibilização de novos resultados de pesquisa e o próprio desenvolvimento do Saeb demandarão modificações nos instrumentos. Este documento cumprirá sua função se for útil para as futuras modificações nos questionários do Saeb; se servir de base para que haja modificações refletidas que representem avanço significativo.

No momento, será adequado concluir com a explicitação de algumas limitações que já podem ser antevistas. Primeiramente, deve ser registrado que há espaço para aprimoramentos relativos à linguagem usada nos questionários e que será importante endereçar esse tipo de questão fora dos cronogramas rígidos que são inevitáveis e necessários no âmbito de uma avaliação. Em segundo lugar, já deixamos indicada a necessidade de aprimoramentos relativos a medidas de motivação e autoestima. Como esses construtos estão no nível do aluno, o interesse primordial não está relacionado com os construtos por eles mesmos, já que o foco central da avaliação de sistemas educacionais concentra-se nos efeitos produzidos pela escola. Relevante será, portanto, poder investigar que características escolares aumentam a motivação e a auto-estima. Infelizmente, as medidas mais corriqueiras sobre motivação e auto-estima não funcionam muito bem no contexto requerido.

Finalmente, cumpre-nos mencionar a adequação dos instrumentos do Saeb e da concepção geral da pesquisa para a investigação de efeitos produzidos pela escola. A mensuração de efeitos produzidos pela escola não pode prescindir de boas medidas cognitivas - as variáveis dependentes -, de medidas acerca do aluno - os controles, em especial os socioeconômicos, sem os quais os estudos acabariam por confundir efeitos produzidos pela escola com situações produzidas pela população que freqüenta as escolas - e de boas medidas acerca da própria escola. Os instrumentos cognitivos e contextuais do Saeb propiciam essas medidas. Além disto, faz-se necessário reconhecer que a estratégia adequada para a investigação de efeitos produzidos pela escola envolve a modelagem multinível e que esta técnica faz exigências adicionais em relação aos dados. Como modelos multiníveis envolvem o foco simultâneo em duas unidades de análise - o estudante e a escola - faz-se necessário a implementação de controles para ambas as unidades de análise. Isto 
também está equacionado no âmbito dos instrumentos do Saeb e os controles necessários podem ser obtidos diretamente ou via a agregação de variável do aluno para níveis superiores.

Outra demanda importante que a modelagem multinível faz acerca dos dados refere-se ao número de observações por escola. Em termos práticos: na modelagem multinível estima-se uma regressão para cada escola, o que pode levar uma amostra enorme a funcionar precariamente, bastando que o grande número de observações seja espalhado em um grande número de escolas, de modo que haja poucas observações por escola. Essa é uma limitação ainda não resolvida do Saeb e que afetará a estimação do efeito escola. Outra limitação igualmente importante relaciona-se com a natureza da variável dependente. Em estudos que tomam medidas cognitivas dos alunos, em mais de uma ocasião, pode-se obter uma medida do valor agregado pela escola no intervalo de tempo entre as medidas cognitivas. Faz todo o sentido procurar explicar o valor agregado pela escola em um certo período - isto é, o aprendizado do aluno durante um certo tempo - em razão de características da escola freqüentada pelo aluno; é precisamente isso o que é feito nas investigações sobre efeito escola. Mas o Saeb não toma mais de uma medida cognitiva de cada aluno. Por isso, o Saeb não oferece medida de valor agregado. O que o Saeb oferece é uma medida do desempenho do aluno. Esse desempenho é conseqüência de uma longa cadeia de aprendizados, que começam muito antes de o aluno freqüentar a escola em que está matriculado. As limitações inerentes às tentativas de explicação do desempenho dos alunos em função das características da escola que o aluno freqüenta no momento da pesquisa são bastante expressivas. É por isso que, freqüentemente, países mantêm um sistema de avaliação da educação com dois tipos de estudos: um desenhado para otimizar o acompanhamento do desempenho dos alunos; outro para identificar características de escolas eficazes e que promovem equidade. É possível transitar de um Saeb com um estilo único de estudo para um Sistema de Avaliação da Educação Básica composto por dois tipos de estudo: um voltado para o acompanhamento do desempenho dos alunos brasileiros; e outro voltado para a determinação dos fatores escolares promotores de qualidade e de equidade. De não menos importância é a constatação de que com a adequada intercalação dos estudos pode-se obter um sistema mais sofisticado e que produza maiores contribuições para gestores de escolas e de sistemas educacionais sem que seja necessário aumento do montante de recursos investidos em um ciclo completo de avaliação. Documento complementar oferecerá subsídios adicionais a este respeito. 


\section{REFERÊNCIAS BIBLIOGRÁFICAS}

BARBOSA, M. E. F.; FERNANDES, C. A escola brasileira faz diferença? Uma investigação dos efeitos da escola na proficiência em Matemática dos alunos da $4^{\text {a }}$ série. In: FRANCO, C. Promoção, ciclos e avaliação educacional. Porto Alegre: ArtMed, p. 155-172, 2001.

BARBOSA, M. E. F.; BELTRÃO, K. I.; FARIÑAS, M. S.; FERNANDES, C.; SANTOS, D. Modelagem do Saeb - 99. Modelos Multinível. Relatório Técnico, Rio de Janeiro, 146 p., 2001.

BRANDÃO, Z. Entre questionários e entrevistas. In: NOGUEIRA, M. A.; ROMANELLI, G.; ZAGO, N. (org.) Família e Escola: trajetórias de escolarização em camadas médias e populares. Petrópolis: Vozes, 2000.

BRESSOUX, P. Les Recherches sur les effets-écoles et les effets-maîtres. Revue Française de Pédagogie, n. 108, p. 91-137, 1994.

BRYK, A.; CAMBURN, E.; SEASHORE LOUIS, K. Professional community in Chicago elementary schools: facilitating factors and organizational consequences. Educational Administration Quarterly. n. 35, p. 751-781, 1999.

COLEMAN, J. S. et al. Equality of educational opportunity. Washington: Government Printing Office, 1966.

CUNHA, L. A. Educação e desenvolvimento educacional no Brasil. Rio de Janeiro: Francisco Alves, 1975.

CREEMERS, B.P.M. The History, value and purpose of school effectiveness studies. In: REYNOLDS, D. et al. (eds.) Advances in School Effectiveness Research and Practice. Oxford: Pergamon, 1994.

ESPOSITO, Y. L.; DAVIS, C.; NUNES, M.M. Sistema de avaliação do rendimento escolar: o modelo adotado pelo Estado de São Paulo. Revista Brasileira de Educação, n. 13, p.25-53, 2000.

FRANCO, C.; MANDARINO, M.; ORTIGÃO, M.I. 2001. Projeto pedagógico de escola promove eficácia e eqüidade em educação? Revista Undime RJ, Rio de Janeiro, v.7, n. 2, p. 30-46, 2002.

FRANCO, C.; SZTAJN, P. Educação em ciências e matemática: identidade e implicações para políticas de formação continuada de professores. In: MOREIRA, A. F. (org.) Política e Currículo. São Paulo: Papirus, 1999. 
FUNDAÇÃO CARLOS CHAGAS. Relatório final: Estudo exploratório Sistema de Avaliação do Ensino Básico. Brasília: Inep, 2001. (mimeo.)

GAUTHIER, C. Por uma teoria da pedagogia: pesquisas contemporâneas sobre o saber docente. Ijuí: Editora UNIJUI, 1998.

GOLDSTEIN, H. Modelos da Realidade: Novas Abordagens para a Compreensão de Processos Educacionais. In: FRANCO, C. (org.) Promoção, ciclos e avaliação educacional. Porto Alegre: ArtMed, p. 85-99, 2001.

GRAY, P. W.; ROWE, K. J.; HOLMES-SMITH, P. Factors afecting students' educational progress: multilevel modelling of educational effectiveness. Paper presented at the International Congress for School Effectiveness, Leeuwarden, the Netherlands, 3-6, January 1995.

HILL, P. W.; ROWE, K. J.; HOLMES-SMITH, P. Factors afecting students' educational progress: multilevel modelling of educational effectiveness. Paper presented at the International Congress for School Effectiveness, Leeuwarden, the Netherlands, 3-6, january 1995.

INEP (2001). Saeb 2001: novas perspectives. Brasília, Inep.

LAREAU, A. Social class differences in family-school relationships: the importance of cultural capital. Sociology of Education, v. 60, p. 73-85, abril 1987.

LEE, V. E. Using multilevel methods to invetigate research questions that involve nested data: examples from education. Estudos em Avaliação Educacional, n. 24, p. 47-68, 2001.

LEE, V. E; BRYK, A. S.; SMITH, J. The Organization of Effective Secondary Schools. In: DARLING-HAMMOND, L. Review of Research in Education. Washington, D.C: American Educational Research Association, p. 171-267, 1993.

MAYER, D. P. Measuring Instructional Practice: can policymakers trust survey data? Educational Evaluation and Policy Analysis, v. 21, n. 1, p. 2945, Primavera, 1999.

MAYER, D.P.; MULLENS, J. E.; MOORE, M.T. Monitoring School Quality: an indicators report. NCES 2001-030. Washington: U.S. Department of Education. National Center for Educaton Statistics, 2000. 
MELLO, G. N. Escolas Eficazes: um tema revisitado. In: XAVIER, A. C. et al. (org.) Gestão Escolar: desafios e tendências. Brasilia: Ipea, p. 329-369, 1994.

MINISTÉRIO DA EDUCAÇÃO E DO DESPORTO - SECRETARIA DE EDUCAÇÃO FUNDAMENTAL. Referenciais para Formação de Professores. Documento Técnico, Brasília, 103 p., 1998.

MINISTÉRIO DA EDUCAÇÃO - INSTITUTO NACIONAL DE ESTUDOS E PESQUISAS EDUCACIONAIS. Matrizes Curriculares de Referência para o Saeb. 2. ed. Brasília, 134 p., 1999.

MORTIMORE, P. School effectiveness and the management of effective learning and teaching. School Effectiveness and School Improvement, v.4, n.4, p. 290310, 1993.

MORTIMORE, P.; SAMMONS, P.; STOLL, L.; LEWIS, D; ECOB, R. School Matters: The Junior Years Wells: Open Books, 1988.

NASCIMENTO, M.G. Formação de professores em serviço: um caminho para a transformação da escola. In: FRANCO, C.; KRAMER, S. (org.) Pesquisa e educação: história, escola e formação de professores. Rio de Janeiro: Ravil, 1997.

PASTORE, J.; SILVA, N. V. Mobilidade Social no Brasil. São Paulo: Makron Books, 2000.

QUEIROZ, G. Processos de formação de professores artistas-reflexivos de Física. Educação e Sociedade, 74, 2001.

RAUDENBUSH, S.W.; RANDALL, P.F.; CHEONG, Y.F. Inequality of Access to Educational Resources: a national report card for eighth-grade Math. Educational Evaluation and Policy Analysis, v. 20, n. 4, p. 253-267, Inverno, 1998.

SAMMONS, P.; HILLMAN, J.; MORTIMORE, P. Key Characteristics of Effective Schools: a review of school effectiveness research. London: Office for Standards in Education [OFSTED], 1995.

SILVA, N.V.; HASENBALG, C. Tendências da Desigualdade Educacional no Brasil. Dados, v. 43, n.3, Rio de Janeiro, 2000.

SOARES, J.F.; SÁTIRO, N.G.D.; MAMBRINI, J. Modelo Explicativo do Desempenho Escolar dos Alunos e Análise dos Fatores do Saeb - 1997. Relatório Técnico. Belo Horizonte: GAME/LME/PROAV, 132 p., março de 2000. 
SOARES, J.F.; BATISTA, J.R.; ALVES, M.T.G.; TEIXEIRA, A.C.A. Fatores Explicativos do Desempenho em Lingua Portuguesa e Matemática: a evidência do Saeb-99. Relatório Técnico, Belo Horizonte: GAME/LME/PROAV, 132 p., novembro de 2000. (mimeo)

SOARES, J.F.; CÉSAR, C.C.; MAMBRINI, J. Determinantes de Desempenho dos Alunos do Ensino Básico Brasileiro: Evidências do Saeb de 1997. In: FRANCO, C. Promoção, ciclos e avaliação educacional. Porto Alegre: ArtMed, p. 121-153, 2001.

TARDIFF, M.; LESSARD, C.; LAHAYE, L. Os professores face ao saber: esboço de uma problemática do saber docente. Teoria e Educação, n.4, 1991.

TARDIFF, M.; LESSARD, C. Le Travail enseignant au quotidien: contribution à l'étude du travail dans les métiers et les professions d'interactions humaines. Laval, Les Presses de l’Université de Laval, 1999.

TEACHMAN, J. et al. Social Capital and the Generation of Human Capital. Social Forces, v. 75, n. 4, p. 1343-1359, 1997.

WILLMS, J. D. Proposal for the Measurement of Socioeconomic Status for the Focused Component of the Student Questionnaire for the OEDC Programme for International Student Assessment (OECD-PISA), 1998. (mimeo)

WILLMS, J. D. Monitoring School Performance. Washington, D.C.: The Falmer Press, 1992.

WILLMS, J. D. Three hypotheses about community effects. In: HELLWELL, J. (ed.) The Contribution of investment in human and social capital to sustained economic growth and well-being. Ottawa: Human Resources Development Canada. (no prelo)

Recebido em: outubro 2003 Aprovado para publicação: novembro 2003 


\section{Anexo \\ A RELAÇÃO ENTRE OS CONSTRUTOS PRIVILEGIADOS E OS ITENS DOS QUESTIONÁRIOS}

Este anexo apresenta o mapeamento entre os construtos privilegiados, sua especificação e detalhamento e a correspondente operacionalização como itens dos questionários. As três primeiras colunas do quadro abaixo simplesmente reproduzem as informações já apresentadas nos quadros 7, 8 e 9. Já a quarta coluna identifica os itens do questionário que operacionalizam cada especificação. Para a leitura da quarta coluna, as letras identificam os Questionários da Escola (E), do Diretor (D), da Turma (T), do Professor (P) e do Aluno (A1 ou A2, correpondentes aos Questionários 1 ou 2 do Aluno), enquanto os números referem-se à numeração de cada item no questionário. Observe-se ainda que há pequenas diferenças nos questionários do aluno, conforme a série considerada. O mapeamento aqui apresentado toma por base os questionários do aluno para a 8a série. Os questionários do Saeb 2001 estão disponíveis em publicação do Inep (2001). Leitores interessados que tenham dificuldade de acesso à mencionada publicação poderão obter os questionários enviando mensagem aos autores do presente artigo.

\section{Quadro 9 - Os construtos privilegiados pelos instrumentos contextuais do Saeb 2001}

\begin{tabular}{|c|c|c|c|}
\hline Nível & Construto & Especificação & $\begin{array}{l}\text { Operacionalização como } \\
\text { Item de Questionário }\end{array}$ \\
\hline \multirow[t]{9}{*}{ Aluno } & \multirow{6}{*}{$\begin{array}{l}\text { Caracterização } \\
\text { sóciodemográfica }\end{array}$} & \multirow{6}{*}{$\begin{array}{l}\text { Idade } \\
\text { Escolaridade dos pais ou dos } \\
\text { responsáveis } \\
\text { Indicadores de renda } \\
\text { Estrutura familiar } \\
\text { Gênero } \\
\text { Etnia }\end{array}$} & A1.3; A1.4 \\
\hline & & & A1.27; A1.28 \\
\hline & & & $\mathrm{A} 1.6 \rightarrow \mathrm{A} 1.22$ \\
\hline & & & $\mathrm{A} 1.23 \rightarrow \mathrm{A} 1.26$ \\
\hline & & & A1.1 \\
\hline & & & A1.2 \\
\hline & Capital social & $\begin{array}{l}\text { Envolvimento da família com a escola } \\
\text { Relação família com aluno } \\
\text { Apoio social recebido via escola }\end{array}$ & $\begin{array}{l}\mathrm{A} 2.1 \rightarrow \mathrm{A} 2.6 \text { e A2.16 } \rightarrow \mathrm{A} 2.19 \\
\mathrm{~A} 2.7 \rightarrow \mathrm{A} 2.15 ; \mathrm{A} 2.35 \\
\mathrm{~A} 2.20 \rightarrow \mathrm{A} 2.25\end{array}$ \\
\hline & Capital cultural & $\begin{array}{l}\text { Recursos culturais disponíveis em } \\
\text { casa }\end{array}$ & $\begin{array}{lll}\text { A1.29 } \rightarrow \text { A1.41; } & \text { A2.29 } \rightarrow \\
\text { A2.32; A1.21 } & & \\
\end{array}$ \\
\hline & $\begin{array}{l}\text { Motivação e auto- } \\
\text { estima }\end{array}$ & Motivação e auto-estima & A2.37; A2.44 \\
\hline
\end{tabular}




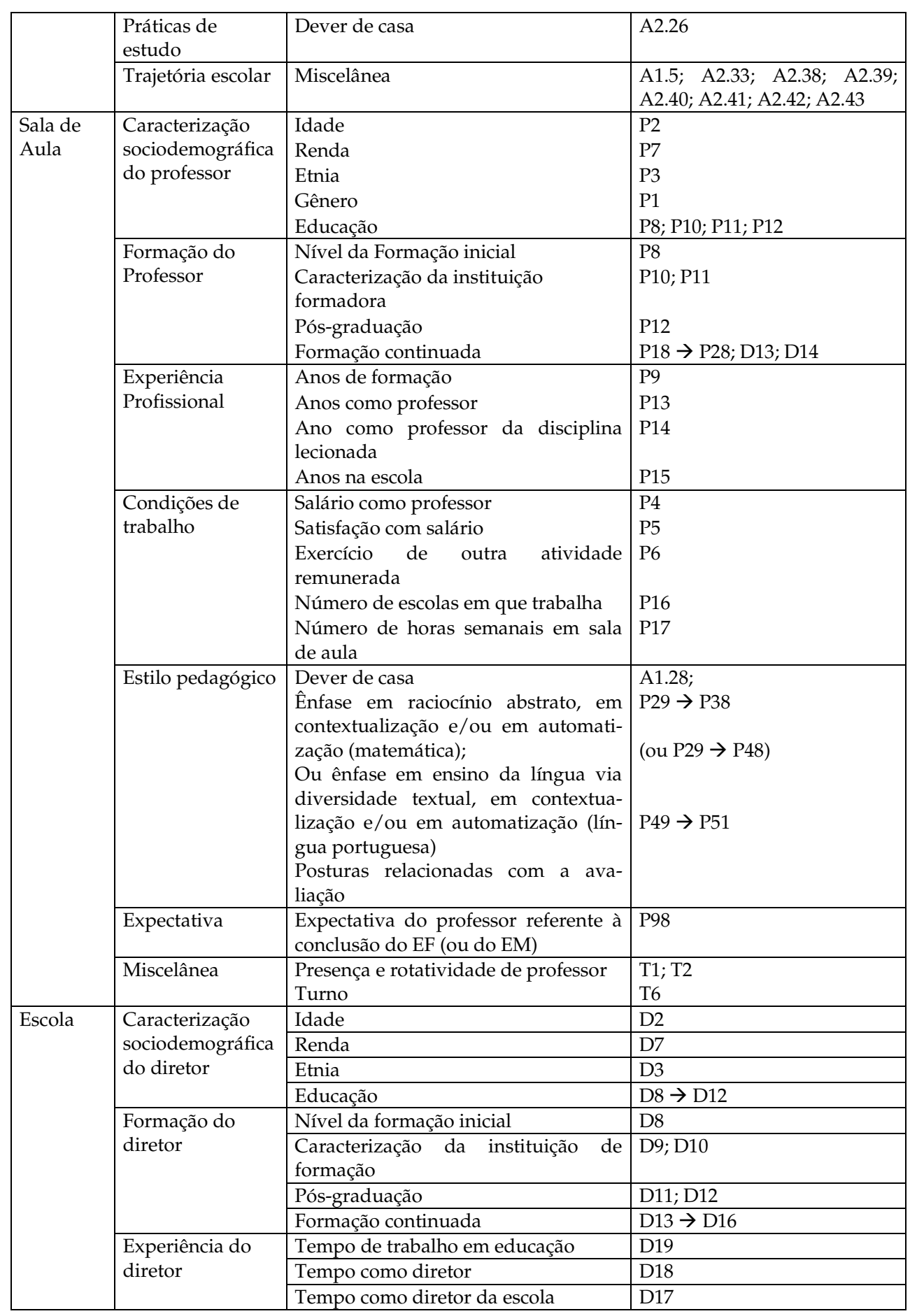




\begin{tabular}{|c|c|c|}
\hline Liderança & Liderança do diretor & P55 $\rightarrow$ P 64 \\
\hline $\begin{array}{l}\text { Condições de } \\
\text { trabalho do } \\
\text { diretor e da } \\
\text { equipe }\end{array}$ & $\begin{array}{l}\text { Carências da escola } \\
\text { Forma de escolha do diretor } \\
\text { Carga horária do diretor } \\
\text { Direção: apoios e interferências }\end{array}$ & $\begin{array}{l}\text { P70 } \rightarrow \text { P75; D47 } \rightarrow \text { D52 } \\
\text { D20 } \\
\text { D21 } \\
\text { D69 } \rightarrow \text { D72 }\end{array}$ \\
\hline $\begin{array}{l}\text { Trabalho } \\
\text { colaborativo }\end{array}$ & $\begin{array}{l}\text { Colaboração entre membros do corpo } \\
\text { docente } \\
\text { Instâncias de gestão da escola } \\
\text { Estabilidade ou rotatividade do corpo } \\
\text { docente }\end{array}$ & $\begin{array}{l}\text { P65 } \rightarrow \text { P69; D13; D14 } \\
\text { P52 } \rightarrow \text { P54; D22 } \rightarrow \text { D29 } \\
\text { D57; D59 }\end{array}$ \\
\hline \begin{tabular}{|l|} 
Organização do \\
ensino e políticas \\
de promoção
\end{tabular} & $\begin{array}{l}\text { Ciclos e sua duração } \\
\text { Políticas para minoração de } \\
\text { repetência e abandono }\end{array}$ & $\begin{array}{l}\text { T3 } \rightarrow \text { T5 } \\
\text { D30; D31 }\end{array}$ \\
\hline Clima acadêmico & $\begin{array}{l}\text { Comprometimento da equipe com } \\
\text { ensino e com aprendizagem } \\
\text { Atitudes frente ao absenteísmo } \\
\text { Existência de "cantinho de livros" e } \\
\text { de murais expressivos (só p/ 4a série) } \\
\text { Organização de atividades voltadas } \\
\text { para a recuperação da aprendizagem } \\
\text { Existência e utilização da biblioteca }\end{array}$ & $\begin{array}{l}\text { P81 } \rightarrow \text { P85; D32 } \rightarrow \text { D36; A1.36 } \\
\text { D37 } \\
\text { T7; T8 } \\
\text { D43; P49 } \rightarrow \text { P51; A1.34; A1.35 } \\
\text { E7 }\end{array}$ \\
\hline Clima Disciplinar & Aspectos do clima disciplinar & P76 $\rightarrow$ P80; D53 $\rightarrow$ D56; D58 \\
\hline $\begin{array}{l}\text { Recursos } \\
\text { pedagógicos }\end{array}$ & Recursos pedagógicos & $\begin{array}{l}\text { P86 } \rightarrow \text { P95 } \\
\text { E6.1 } \rightarrow \text { E6.8 }\end{array}$ \\
\hline $\begin{array}{l}\text { Situação das } \\
\text { instalações e } \\
\text { equipamentos }\end{array}$ & $\begin{array}{l}\text { Estado de conservação do prédio } \\
\text { Aspectos ambientais } \\
\text { Limpeza } \\
\text { Segurança das instalações } \\
\text { Existência e estado de recursos } \\
\text { pedagógicos } \\
\text { Situação geral da infra-estrutura } \\
\end{array}$ & $\begin{array}{l}\text { E1.1 } \rightarrow \text { E1.8; E4.7 } \\
\text { E2.1 } \rightarrow \text { E2.3 } \\
\text { E3.1 } \rightarrow \text { E3.7 } \\
\text { E4.1 } \rightarrow \text { E4.7 } \\
\text { E6.1 } \rightarrow \text { E6.8 } \\
\text { E8 }\end{array}$ \\
\hline $\begin{array}{l}\begin{array}{l}\text { Atividades } \\
\text { extracurriculares }\end{array} \\
\end{array}$ & \begin{tabular}{|l|} 
Voltadas para alunos \\
Voltadas para a comunidade
\end{tabular} & $\begin{array}{l}\text { D60 } \rightarrow \text { D65 } \\
\text { D66 }\end{array}$ \\
\hline Miscelânea & $\begin{array}{l}\text { Admissão de alunos } \\
\text { Critérios de formação de turmas } \\
\text { Critérios de atribuição de professores } \\
\text { para as turmas } \\
\text { Oferecimento de programas direcio- } \\
\text { nados a alunos com necessidades } \\
\text { especiais } \\
\text { Acesso aos resultados do Saeb }\end{array}$ & $\begin{array}{l}\text { D45; } \\
\text { D67 } \\
\text { D44 } \\
\text { D38 } \rightarrow \text { D42 } \\
\text { D68 } \\
\end{array}$ \\
\hline
\end{tabular}

